\title{
Interactive role of breast cancer on dyslipidemia and hypertension metabolic risk according to treatment exposure and menopausal status
}

Research Article

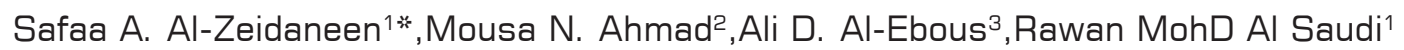 \\ ${ }^{1}$ Department of Allied Medical Sciences, Al-Zarqa University College, Al-Balqa \\ Applied University, Al-Salt, Jordan
}

2Department of Nutrition and Food Technology, Faculty of Agriculture, the

University of Jordan, Amman, Jordan

${ }^{3}$ Breast Cancer Unite, Department of General Surgery, King Hussein Medical

Center, Amman, Jordan

Received 30 June 2018; Accepted 29 April 2019

\begin{abstract}
Background: Breast cancer $(\mathrm{BC})$ is the principal cause of cancer related deaths among women worldwide. The available evidence suggests that cardio-metabolic risk factors such as dyslipidemia and hypertension may contribute differently to breast cancer severity and pathogenesis. The aim of this study is to evaluate the interactive role of BC on dyslipidemia and HTN risk according to the type of treatment exposure and menopausal status. Patients and methods: Observational experimental design implemented; permit to include 134 newly-diagnosed patients who were naïve to any type of treatment interventions and 262 recently-diagnosed patients during their first three months of treatments' exposure including chemotherapy treatments. Patients with breast cancer were evaluated for dyslipidemia and hypertension biomarkers. Results: About 5.0\% of breast cancer patients had dyslipidemia. The prevalence of increased triglycerides and total cholesterol were more frequent $(p<0.05)$ in recently-diagnosed group than in newly-diagnosed patients. While $23 \%$ of patients had overt hypertension, with higher $(p<0.05)$ prevalence in chemo group $(28 \%)$, triglycerides was higher $(p<0.05)$ in postmenopausal than premenopausal BC patients $(221.0 \pm 5.9 \mathrm{vs} .195 \pm 4.7 \mathrm{mg} / \mathrm{dl})$. Similarly, the prevalence of abnormal systolic blood pressure ( $9 \%$ vs. $5 \%)$ and diastolic blood pressure $(11 \%$ vs. $7 \%)$ was higher $(p<0.05)$ in postmenopausal patients. Conclusions: Dyslipidemia and hypertension biomarkers were prevalent among breast cancer patients and the risk increased in postmenopausal women and after treatments' exposure specially chemotherapy. This conclusion requires a closer attention by healthcare professionals in order to improve the outcomes after diagnosis and to enhance treatment exposure regarding postmenopausal women.
\end{abstract}

Keywords: Breast cancer • chemotherapy • hypertension • lipid profile

\section{Introduction}

Breast cancer $(\mathrm{BC})$ is a disease characterized by the growth of malignant cells in the mammary glands. BC is the most frequent cancer in women, which is malignant in most cases, and is the leading cause of cancer related deaths among women worldwide. It accounts for about $28 \%$ of all cancers in Europe and United States. ${ }^{[1]}$ In Jordan, BC is the most frequent cancer type amongst female cancers, accounting for about $37 \%$ of all cancers and about $19 \%$ of all newly diagnosed cancer cases followed by colorectal cancer. According to a published study in the United Kingdom, around $7 \%$ of female BC is related to modifiable lifestyle and environmental factors. [2] Although, many risk and prognostic factors of $B C$ have been documented, an insight view of $B C$ severity and prognosis is still not clarified. ${ }^{[3]}$ Evidences suggest that cardio-metabolic risk factors such as dyslipidemia and hypertension (HTN) may have different influences on BC severity and pathogenesis. ${ }^{[4-6]}$ Dyslipidemia is characterized by an elevation in total cholesterol concentration, low-density lipoprotein cholesterol 
(LDL-C), triglyceride (TG) concentrations and a reduction in high-density lipoprotein cholesterol (HDL-C). Mechanisms for such relationship between dyslipidemia and BC risk are unknown; however, previous studies proposed that abnormal lipid metabolism along with insulin resistance may be related to $B C$ pathogenesis and $\mathrm{BC}$ subtypes ${ }^{[4]}$ Moreover, BC tissues had faster TG turnover in comparison to normal tissue. ${ }^{[6]}$ Evidence of possible effect of dyslipidemia and HTN on BC risk is inconclusive and very limited. ${ }^{[4,5,7]}$

In Jordan, dyslipidemia and HTN are significantly prevalent among Jordanian females and males. ${ }^{[8-10]}$ However, there are no studies on BC severity and HTN, nor on dyslipidemia risk factors. Furthermore, studies that evaluate the impact of treatment exposure on dyslipidemia and HTN are also lacking. Subsequently, the objective of the current study is to evaluate the interactive role of $\mathrm{BC}$ on Dyslipidemia and HTN risk among Jordanian women according to the type of treatment exposure and menopausal status.

\section{Subjects and Methods}

\subsection{Study sample and design}

In this study, 396 Jordanian female patients diagnosed with breast cancer (BC) aged between 25-65 years attending $\mathrm{BC}$ clinics at the Jordanian Royal Medical Services in Jordan for the management and follow-up of their conditions during the period from January 2013 to July 2014. Patients were screened for leptin hormone level. The experimental design was prospective observational that permitted to include 134 newlydiagnosed BC patients who were naïve to any type of treatment interventions and 262 recently-diagnosed BC patients (up to three months) who were exposed to any type of treatment interventions. Recently, group members were sub-divided into sub-groups to control exposure to chemotherapy. The study design also permitted to include pre- and postmenopausal BC patients for hormonal balance control. The sample size (396) was statistically sound and accounts for about $50 \%$ of BC cases in the year 2011 . The median age of females with BC in Jordan is 51 years old, and $80 \%$ of the cases age ranged between the ages of 25 and 65 years old. ${ }^{[11]}$ Exclusion criteria was also determined; any clinical or laboratory evidence of congestive heart failure, coronary disease, chronic renal failure, polycystic ovary syndrome, thyroid diseases, pregnancy and lactation. Moreover, subjects below 25 or above 65 years of age, type I diabetes mellitus, epilepsy and those taking medical herbs were also excluded.
Also, any subject who did not fit the inclusion criteria was excluded. This study was conducted according to the Declaration of Helsinki (2008, including 2013 amendments) and willingly; all participants had read and signed an informed consent form at the start of the study. The Royal Medical Services Ethical Committee approved this study (reference number 1/2013).

\subsection{Data collection}

A validated and reliable questionnaire was adopted for data collection which included personal information, health, anthropometric and biochemical measurements.

\subsubsection{Anthropometric measurements}

Anthropometric indicators comprised of: height, weight, waist circumference (WC) and hip circumference (HC) were measured in duplicates with subjects lightly clothed and without shoes. These indicators were performed by the investigator following the methodological protocol. [12] The body mass index (BMI) was calculated as weight in kilograms divided by height in meters squared. The $\mathrm{BMI} \geq 30 \mathrm{~kg} / \mathrm{m}^{2}$ was considered obese. ${ }^{[13]}$ The waist to hip ratio (WHpR) was calculated as WC divided by $\mathrm{HC}$, while the waist to height ratio ( $\mathrm{WHtR}$ ) was calculated as WC divided by Height.

\subsubsection{Biochemical analyses}

Blood samples were collected after minimum 12 hours of fasting. The serum had been harvested and stored at $-80^{\circ} \mathrm{C}$ for analysis. Biochemical measurements were analyzed in Princess Eman Center for Laboratory Research and Science. The following laboratory measurements were performed in duplicates for each subject and the mean values were taken in subsequent calculations for biomarkers such as fasting blood glucose (FBG), fasting blood insulin (FBI) and C-peptide. For the analysis of triglycerides (TG), total cholesterol (TC), high density lipoprotein (HDL-C) and low density lipoprotein (LDL-C) in human serum, the enzymatic colorimetric assay was applied. The upper normal limits used for TC and LDL-C, were $200 \mathrm{mg} / \mathrm{dl}$ and $150 \mathrm{mg} / \mathrm{dl}$, respectively. Lower limit for HDL was $<50 \mathrm{mg} / \mathrm{dl}$. Plasma glucose was determined by the glucose dehydrogenase method (Wako Pure Chemical Industries, Ltd., Osaka, Japan). C-peptide was measured by a solid-phase, two-site chemiluminescent immunoassay (IMMULITE 2000 C-peptide assay, Siemens AG, Erlangen, Germany). 
The fasting blood insulin levels were quantitatively determined by chemiluminescent microparticle immunoassay (CMIA) technology (ARCHITECT Insulin assay, Abbott Laboratories, IL, USA). The Manual Enzyme-Linked Immunosorbent Assay (ELISA) was used for the quantitative determination of leptin levels in serum by an enzyme immunoassay method (dbcDiagnostics Biochem Canada Inc., Canada). The insulin sensitivity was then calculated using HOMA according to the following formula ${ }^{[14]}$ :

$\log (\mathrm{HOMA})=\log [\mathrm{FBG}(\mathrm{mmol} / \mathrm{L}) \times \mathrm{FBI}(\mu \mathrm{U} / \mathrm{ml}) / 22.5]$

\subsubsection{Blood pressure}

Two blood pressure readings were recorded in an upright sitting position by a licensed staff nurse using a standard mercury sphygmomanometer after seating the subjects for at least 15 minutes. The average value was recorded and blood pressure was considered high if SBP $\geq 130$ $\mathrm{mmHg}$ and/or DBP $\geq 85 \mathrm{mmHg} .{ }^{[15]}$ The cut-off points for SBP, DBP, TG, and HDL-C were determined based on Alberti et al. definition of metabolic abnormalities. ${ }^{[15]}$ We consider high normal DBP and DBP levels among BC patients as a HTN risk as that of metabolic syndrome. ${ }^{[15]}$

\section{Statystical Analysis}

Statistical analyses were performed using Statistical Package for the Social Sciences (SPSS), version 10.0 (SPSS Inc., Chicago, USA). For all analyses, a probability value of $<0.05$ was considered statistically significant. Results were expressed according to the study needs as either frequency distribution with their percentages (\%) or means \pm standard error of mean (SEM). Frequency distribution and percentages or means \pm SEM were performed for the health characteristics, prevalence of dyslipidemia and hypertension, and the menopausal status was compared according to the type of treatment exposure. The independent sample t-test or the chi-squared test were used between high density lipoprotein (HDL-C) and low density lipoprotein (LDL-C), systolic and diastolic blood pressure, and menopausal status in addition to various BC status.

\section{Results}

Dyslipidemia and hypertension characteristics of the study sample according to treatment exposure are shown in Table 4.1. Systolic blood pressure (SBP) was higher $(p<0.05)$ in chemo $(123.0 \pm 0.9 \mathrm{mmHg})$ than in non-chemo $(119.5 \pm 1.2 \mathrm{mmHg})$ and newly-diagnosed $(119.1 \pm 1.1 \mathrm{mmHg})$ groups. Total cholesterol (TC) and triglycerides (TG) were higher $(p<0.05)$ in recentlydiagnosed $(244.7 \pm 3.0$ vs. $211.1 \pm 4.7 \mathrm{mg} / \mathrm{dl})$ compared to newly-diagnosed $(227.1 \pm 4.3$ vs. $195.7 \pm 5.8 \mathrm{mg} /$ dl) group. High density lipoprotein cholesterol (HDL-C) was lower $(p<0.05)$ in non-chemo $(42.9 \pm 1.0 \mathrm{mg} /$ dl) compared to chemo $(47.6 \pm 0.7 \mathrm{mg} / \mathrm{dl})$ and newlydiagnosed $(47.8 \pm 0.8 \mathrm{mg} / \mathrm{dl}$ ) groups (Table 4.1).

Prevalence of the dyslipidemia risk factors and hypertension according to treatment exposure are presented in Table 4.2. The prevalence of elevated SBP ( $\geq 130 \mathrm{mmHg}$ ) was significantly $(p<0.05)$ higher in chemo group (19.3\%) than non-chemo $(9.3 \%)$ and newly-diagnosed (10.4\%) groups (Table 4.9). The prevalence of increased TG ( $\geq 150 \mathrm{mg} / \mathrm{dl})$ and TC $(\geq 200$ $\mathrm{mg} / \mathrm{dl})$ were more frequent $(p<0.05)$ in the recentlydiagnosed group ( $82.4 \%$ vs. $80.9 \%$ ) than in the newlydiagnosed patients $(76.1 \%$ vs. $67.2 \%)$ for TG and TC, respectively. The prevalence of low HDL-C $(<50 \mathrm{mg} /$ dl) was higher $(p<0.05)$ in non-chemo group $(81.4 \%)$ than chemo $(63.6 \%)$ and newly-diagnosed $(61.2 \%)$ groups. No statistical significant difference was found with respect to the frequency of high DBP (18.4\%), ( $p \geq$ 0.05 ) among the study groups (Table 4.2).

Prevalence of dyslipidemia risk factors and hypertension in pre and post-menopause according to treatment exposure are shown in Table 4.3. The prevalence of abnormal TG and HDL-C respectively, was significantly higher $(p<0.05)$ in the premenopausal $(43.4 \%$ and $38.4 \%)$ than in the postmenopausal BC patients $(36.9 \%$ and $28.3 \%)$. Compared to the premenopausal BC patients, the postmenopausal BC patients had significantly higher $(p<0.05)$ prevalence of abnormal SBP (9.3\% vs. $4.8 \%)$ and DBP (11.4\% vs. 7.1\%) (Table 4.3).

Dyslipidemia and hypertension characteristic in pre and postmenopausal women according to treatment exposure are shown in Table 4.4. In postmenopausal BC patients, SBP was higher $(p<0.05)$ in the recentlydiagnosed $(136.2 \pm 1.2 \mathrm{mmHg})$ compared to the newly-diagnosed group (121.1 $\pm 1.7 \mathrm{mmHg})$. Statistical significant differences were found $(p<0.05)$ between postmenopausal and premenopausal BC patients in TG $(221.0 \pm 5.9$ vs. $195 \pm 4.7 \mathrm{mg} / \mathrm{dl})$, SBP $(125.0 \pm 1.0$ vs. $118 \pm 0.8 \mathrm{mmHg})$. However, no statistical significant difference was found with $(p \geq 0.05)$ in HDL-C (47.0 \pm 0.8 vs. $46.0 \pm 0.6 \mathrm{mg} / \mathrm{dl})$ and DBP $(80.0 \pm 0.7$ vs. $78.0 \pm 0.6$ $\mathrm{mmHg}$ ) among postmenopausal and premenopausal BC patients, respectively (Table 4.4).

Age-controlled partial correlation coefficients are presented in Table 4.5. The WHtR and WC respectively 
Table 4.1: Dyslipidaemia and hypertension characteristics according to treatment exposure ${ }^{(1-3)}$

\begin{tabular}{|c|c|c|c|c|c|c|c|c|c|c|}
\hline \multirow{3}{*}{ Character } & \multirow{2}{*}{\multicolumn{2}{|c|}{$\begin{array}{c}\text { Newly- } \\
\text { diagnosed }(n= \\
134)\end{array}$}} & \multicolumn{6}{|c|}{ Recently - diagnosed $(n=262)$} & \multirow{2}{*}{\multicolumn{2}{|c|}{$\begin{array}{l}\text { Whole sample } \\
\qquad(n=396)\end{array}$}} \\
\hline & & & \multirow{2}{*}{\multicolumn{2}{|c|}{$\begin{array}{c}\text { Non- chemo } \\
(n=86)\end{array}$}} & \multirow{2}{*}{\multicolumn{2}{|c|}{$\begin{array}{c}\text { Chemo } \\
(n=176) \\
\text { Mean } \pm \text { SEM }\end{array}$}} & \multicolumn{2}{|c|}{$\begin{array}{c}\text { Total } \\
(n=262)\end{array}$} & & \\
\hline & Mear & SEM & & & & & Mear & SEM & Mee & SEM \\
\hline SBP (mmHg) & 119.1 & $1.1^{\mathrm{a}}$ & 119.5 & $1.2^{\mathrm{a}}$ & 123.0 & $0.9^{b}$ & 121.9 & $0.8^{\mathrm{a}}$ & 120.9 & 0.6 \\
\hline DBP (mmHg) & 78.4 & $1.0^{\mathrm{a}}$ & 78.0 & $0.8^{\mathrm{a}}$ & 79.6 & $0.7^{\mathrm{a}}$ & 79.1 & $0.5^{\mathrm{a}}$ & 78.8 & 0.5 \\
\hline HDL-C(mg/dl) & 47.8 & $0.8^{a}$ & 42.9 & $1.0^{\mathrm{b}}$ & 47.6 & $0.7^{\mathrm{a}}$ & 45.6 & $0.6^{b}$ & 46.4 & 0.5 \\
\hline LDL-C (mg/dl) & 126.9 & $9.0^{\mathrm{a}}$ & 141.0 & $3.4^{\mathrm{a}}$ & 128.8 & $2.8^{\mathrm{a}}$ & 132.8 & $2.2^{\mathrm{a}}$ & 130.8 & 3.4 \\
\hline TG (mg/dl) & 195.7 & $5.8^{\mathrm{a}}$ & 221.8 & $8.9^{b}$ & 205.9 & $5.6^{b}$ & 211.1 & $4.7^{\mathrm{b}}$ & 205.9 & 3.7 \\
\hline
\end{tabular}

1. Values are given as mean \pm SEM.

2. Values in rows with different superscripts are significantly different $(p<0.05)$.

3. Abbreviations and definitions: newly diagnosed: newly- diagnosed: breast cancer patients who are not exposed to any type of interventions; recentlydiagnosed: breast cancer patients within 3 months of diagnosis who are either exposed (chemo) or not exposed (non- chemo) to chemical therapy; SEM: stander error of mean; SBP: systolic blood pressure, DBP: diastolic blood pressure, TC: total cholesterol; TG: triglycerides; HDL-C: high density lipoprotein cholesterol; LDL-C: Iow density lipoprotein cholesterol.

Table 4.2: Prevalence of the dyslipidemia risk factors and hypertension according to treatment exposure ${ }^{(1-4)}$

\begin{tabular}{|c|c|c|c|c|c|c|c|c|c|c|c|}
\hline \multirow{3}{*}{ Variables } & \multirow{3}{*}{$\begin{array}{l}\text { Cut-off } \\
\text { points }\end{array}$} & \multirow{2}{*}{\multicolumn{2}{|c|}{$\begin{array}{c}\text { Newly- } \\
\text { diagnosed } \\
(n=134)\end{array}$}} & \multicolumn{6}{|c|}{ Recently - diagnosed $(n=262)$} & \multirow{2}{*}{\multicolumn{2}{|c|}{$\begin{array}{l}\text { Whole sample } \\
\qquad(n=396)\end{array}$}} \\
\hline & & & & \multicolumn{2}{|c|}{$\begin{array}{c}\text { Non- chemo } \\
(n=86)\end{array}$} & \multicolumn{2}{|c|}{$\begin{array}{c}\text { Chemo } \\
(n=176)\end{array}$} & \multicolumn{2}{|c|}{$\begin{array}{c}\text { Total } \\
\text { (n = 262) } \\
\end{array}$} & & \\
\hline & & $\mathbf{n}$ & $\%$ & $\mathbf{n}$ & $\%$ & $\mathbf{n}$ & $\%$ & $\mathbf{n}$ & $\%$ & $\mathbf{n}$ & $\%$ \\
\hline SBP (mmHg) & $>130$ & 14 & $10.4^{a}$ & 8 & $9.3^{a}$ & 34 & $19.3^{b}$ & 42 & $16.0^{b}$ & 56 & 14.1 \\
\hline DBP (mmHg) & $>85$ & 24 & $17.9^{a}$ & 11 & $12.8^{\mathrm{a}}$ & 38 & $21.6^{a}$ & 49 & $18.7^{a}$ & 73 & 18.4 \\
\hline \multicolumn{2}{|c|}{ Overt hypertension* } & 31 & 23.1 & 10 & 11.6 & 49 & 27.8 & 59 & 22.5 & 90 & 22.7 \\
\hline HDL-C (mg/dl) & $<50$ & 82 & $61.2^{\mathrm{a}}$ & 70 & $81.4^{b}$ & 112 & $63.6^{\mathrm{a}}$ & 182 & $69.5^{b}$ & 264 & 66.7 \\
\hline TG (mg/dl) & $>150$ & 102 & $76.1^{\mathrm{a}}$ & 73 & $84.9^{b}$ & 143 & $81.2^{\mathrm{b}}$ & 216 & $82.4^{\mathrm{b}}$ & 318 & 80.3 \\
\hline TC (mg/dl) & $>200$ & 90 & $67.2^{\mathrm{a}}$ & 75 & $87.2^{b}$ & 137 & $77.8^{b}$ & 212 & $80.9^{b}$ & 302 & 76.3 \\
\hline \multicolumn{2}{|c|}{ Overt dyslipidemia* } & 7 & 5.2 & 2 & 2.3 & 10 & 5.7 & 12 & 4.6 & 19 & 4.8 \\
\hline
\end{tabular}

1. Values given as number of patients $(n)$ and their percentages out of $(N)$.

2. Values in rows with different superscripts are significantly different $(p<0.05)$.

3. Cut-off points were based on Albertiet al., 2009 definition of metabolic abnormalities. ${ }^{[15}$

4. Abbreviations and definitions: newly-diagnosed: breast cancer patients who are not exposed to any type of interventions; recently-diagnosed: breast cancer patients within 3 months of diagnosis who are either exposed (chemo) or not exposed (non-chemo) to chemical therapy; SEM: stander error of mean; SBP: systolic blood pressure, DBP: diastolic blood pressure, TC: total cholesterol; TG: triglycerides; HDL-C: high density lipoprotein cholesterol; LDL-C: low density lipoprotein cholesterol.

* The study patients who are on anti-hypertensive or lipid lowering agents.

Table 4.3: Prevalence of dyslipidemia risk factors and hypertension in pre and postmenopause according to treatment exposure(1-5)

\begin{tabular}{|c|c|c|c|c|c|c|c|c|c|c|c|c|}
\hline \multirow{3}{*}{$\begin{array}{l}\text { Metabolic } \\
\text { risk }\end{array}$} & \multicolumn{4}{|c|}{ Newly-diagnosed $(N=134)$} & \multicolumn{4}{|c|}{ Recently-diagnosed (N = 262) } & \multicolumn{4}{|c|}{ Whole sample ( $N=396)$} \\
\hline & \multicolumn{2}{|c|}{$\begin{array}{c}\text { Premeno- } \\
\text { pause } \\
(\mathbf{N}=\mathbf{8 0})\end{array}$} & \multicolumn{2}{|c|}{$\begin{array}{c}\text { Postmeno- } \\
\text { pause } \\
(N=54)\end{array}$} & \multicolumn{2}{|c|}{$\begin{array}{c}\text { Premeno- } \\
\text { pause } \\
(N=149)\end{array}$} & \multicolumn{2}{|c|}{$\begin{array}{c}\text { Postmeno- } \\
\text { pause } \\
(N=113)\end{array}$} & \multicolumn{2}{|c|}{$\begin{array}{c}\text { Premeno- } \\
\text { pause } \\
(\mathbf{N}=229)\end{array}$} & \multicolumn{2}{|c|}{$\begin{array}{c}\text { Postmeno- } \\
\text { pause } \\
(N=167)\end{array}$} \\
\hline & $\mathbf{n}$ & $\%$ & $\mathbf{n}$ & $\%$ & $\mathbf{n}$ & $\%$ & $\mathbf{n}$ & $\%$ & $\mathbf{n}$ & $\%$ & n & $\%$ \\
\hline $\mathrm{SBP}^{*}(\mathrm{mmHg})$ & 6 & 4.5 & 8 & 6.0 & 13 & 5.0 & 29 & 11.1 & 19 & 4.8 & 37 & 9.3 \\
\hline $\mathrm{DBP}^{*}(\mathrm{mmHg})$ & 8 & 6.0 & 16 & 11.9 & 20 & 7.6 & 29 & 11.1 & 28 & 7.1 & 45 & 11.4 \\
\hline HDL*(mg/dl) & 48 & 35.8 & 34 & 25.4 & 104 & 39.7 & 78 & 29.9 & 152 & 38.4 & 112 & 28.3 \\
\hline $\mathrm{TG}^{\star}(\mathrm{mg} / \mathrm{dl})$ & 56 & 41.8 & 46 & 34.3 & 116 & 44.3 & 100 & 38.3 & 172 & 43.4 & 146 & 36.9 \\
\hline
\end{tabular}

1. Documented international cut-off points: Alberti et al. ${ }^{[15]}$

2. Values are given as number of patients (n) and their percentages out of $(\mathrm{N})$.

3. $\left(^{\star}\right)$ Significantly $(p<0.05)$ different between pre and postmenopausal women for each treatment exposure and whole sample.

4. Cross differences between treatment exposure groups were not significant $(p>0.05)$.

5. Abbreviations and definitions: newly diagnosed: breast cancer patients who are not exposed to any type of interventions; recently diagnosed: breast cancer patients within 3 months of diagnosis who are either exposed (chemo) or not exposed (non- chemo) to chemical therapy; SBP: systolic blood pressure; DBP: diastolic blood pressure; TG: triglycerides; HDL-C: high density lipoprotein. 
Table 4.4: Dyslipidemia and hypertension characteristic in pre and postmenopause women according to treatment exposure ${ }^{(1-5)}$

\begin{tabular}{|c|c|c|c|c|c|c|c|c|c|c|c|c|}
\hline \multirow{3}{*}{$\begin{array}{l}\text { Metabolic } \\
\text { risks }\end{array}$} & \multicolumn{4}{|c|}{ Newly-diagnosed ( $N=134)$} & \multicolumn{4}{|c|}{ Recently-diagnosed ( $N=262)$} & \multicolumn{4}{|c|}{ Whole sample ( $N=396)$} \\
\hline & \multicolumn{2}{|c|}{$\begin{array}{c}\text { Premeno- } \\
\text { pause } \\
(\mathbf{N}=\mathbf{8 0})\end{array}$} & \multicolumn{2}{|c|}{$\begin{array}{c}\text { Postmeno- } \\
\text { pause } \\
(\mathrm{N}=54)\end{array}$} & \multicolumn{2}{|c|}{$\begin{array}{c}\text { Premeno- } \\
\text { pause } \\
(N=149)\end{array}$} & \multicolumn{2}{|c|}{$\begin{array}{c}\text { Postmeno- } \\
\text { pause } \\
(N=113)\end{array}$} & \multicolumn{2}{|c|}{$\begin{array}{c}\text { Premeno- } \\
\text { pause } \\
(N=229)\end{array}$} & \multicolumn{2}{|c|}{$\begin{array}{c}\text { Postmeno- } \\
\text { pause } \\
(N=167)\end{array}$} \\
\hline & Mean \pm & SEM & Mean & \pm SEM & Mean \pm & SEM & Mean & SEM & Mean & SEM & Mean & SEM \\
\hline $\mathrm{SBP}^{\star}(\mathrm{mmHg})$ & 117.1 & 1.5 & 121.1 & $1.7^{\mathrm{a}}$ & 118.5 & 0.9 & 136.2 & $1.2^{\mathrm{b}}$ & 118.0 & 0.8 & 129.3 & 1.0 \\
\hline DBP(mmHg) & 76.6 & 1.4 & 80.9 & 1.1 & 78.3 & 0.6 & 80.2 & 1.0 & 78.0 & 0.6 & 80.0 & 0.7 \\
\hline HDL-C(mg/dl) & 47.9 & 0.9 & 47.7 & 1.6 & 44.8 & 0.8 & 46.7 & 0.9 & 46.0 & 0.6 & 47.0 & 0.8 \\
\hline$T^{*}{ }^{*}(\mathrm{mg} / \mathrm{dl})$ & 182.5 & 6.9 & 215.3 & 9.6 & 201.7 & 6.1 & 223.5 & 7.4 & 195.0 & 4.7 & 221.0 & 5.9 \\
\hline
\end{tabular}

1. Documented international cut-off points: Alberti, et al. ${ }^{[15]}$

2. Values are given as mean \pm SEM

3. $\left(^{\star}\right)$ Significant differences $(\mathrm{p}<0.05)$ between pre and postmenopausal women for treatment exposure groups and whole sample.

4. Values in rows with different superscripts are significantly different among treatment exposure groups $(p<0.05)$. None of other values in rows show significant differences $(p>0.05)$.

5. Abbreviations and definitions: newly diagnosed: breast cancer patients who are not exposed to any type of interventions; recently diagnosed: breast cancer patients within 3 months of diagnosis who are either exposed (chemo) or not exposed (non- chemo) to chemical therapy; SBP: systolic blood pressure; DBP: diastolic blood pressure; TG: triglycerides; HDL: high density lipoprotein; SEM: stander error of mean.

Table 4.5: Age-controlled partial correlation coefficients of dyslipidemia risk factors and hypertension with obesity indices and selected biomarkers in the study sample $e^{(1-2)}$

\begin{tabular}{|c|c|c|c|c|c|c|c|}
\hline Metabolic risks & BMI & WC & WHpR & WHtR & leptin & HOMA & C-peptide \\
\hline SBR(mmHg) & 0.04 & 0.08 & 0.12 & 0.08 & 0.10 & $0.14^{\star \star}$ & 0.03 \\
\hline DBR (mmHg) & 0.01 & $0.17^{\star \star \star}$ & $0.15^{\star \star}$ & $0.13^{*}$ & 0.08 & $0.10^{*}$ & -0.02 \\
\hline HDL-C(mg/dl) & $-0.11^{\star}$ & $-0.11^{\star}$ & -0.09 & $-0.13^{\star *}$ & -0.02 & 0.02 & 0.03 \\
\hline TG (mg/dl) & 0.05 & $0.16^{\star \star \star}$ & 0.08 & $0.15^{\star \star}$ & $-0.11^{\star}$ & 0.03 & 0.02 \\
\hline
\end{tabular}

1. *: $(p<0.05) ; * *:(p<0.01) ; * * *:(p<0.001)$.

2. Abbreviations and definitions: newly diagnose: BMI: body mass index; WC: waist circumferences $\mathrm{cm}$; WHtR: waist to height ratio; WHpR: waist to hip ratio; HOMA: homeostasis model assessment according to the following formulas ${ }^{[14]}$ : $\log (\mathrm{HOMA})$ as log $\left[\mathrm{FBG}(\mathrm{mmol} / \mathrm{L}) \times \mathrm{FBI}(\mu \mathrm{U} / \mathrm{ml}) / 22 .{ }^{[15]}\right.$

were significantly $(p<0.05)$ correlated with DBP $(r=$ 0.13 vs. $r=0.17)$, HDL-C ( $r=-0.13$ vs. $r=-0.11)$ and TG ( $r=0.15$ vs. $r=0.16)$. The HDL-C was negatively correlated $(p<0.05)$ with BMI $(r=-0.11)$, WC $(-0.11)$ and WHtR (-0.13). While TG was negatively correlated $(p<0.05)$ with leptin level $(r=-0.11)$. Both SBP and DBP were strongly correlated $(p<0.05)$ with $\operatorname{HOMA}(r=0.14)$ and $(r=0.10)$, respectively (Table 4.5$)$.

\section{Discussion}

\subsection{Dyslipidemia and breast cancer}

In this study, the prevalence of known cases of dyslipidemia was $5 \%$. Nevertheless, high triglycerides (TG) and low high density lipoprotein cholesterol (HDL-C) were observed in $80 \%$ and $67 \%$ of study sample, respectively. Results from this study seem to be higher than those reported in non-BC patients in Jordan. Studies investigating dyslipidemia in breast cancer (BC) patients are scarce. A study by Hammoudeh et al. showed that the prevalence of high TG was $55 \%$ and low HDL-C was 39\%. ${ }^{[8]}$ Another study by Khader et al. found that $39 \%$ of women had high TG and $28 \%$ had low HDL-C. ${ }^{\left[{ }^{9]}\right.}$ Furthermore, a resembling study conducted in Italy among BC patients reflected lower results; with prevalence of high TG and low HDL-C represented in the percentage of $34.7 \%$ and $38.4 \%$, respectively. ${ }^{[16]}$ This variation emerged from several reasons. Improper data reporting provided by participants regarding the duration of fasting, the inconsistent definition of dyslipidemia, characteristics of the target group and different study design could all justify this variation.

In the current study, the prevalence of high TG and low HDL-C level were significantly different among recently-and newly-diagnosed BC patients. These differences may be due to possible medical interventions such as chemotherapy or surgery. Present study showed that prevalence of high TG and low HDL-C level in premenopausal women was higher than in postmenopausal women, but the mean value of TG level was significantly higher $(p<0.05)$ in postmenopausal BC women. In accordance, higher risk of dyslipidemia in BC patients over 60 years old has been reported. ${ }^{[17,18]}$ In a longitudinal prospective study 
by Furberg et al. concluded that the serum HDL-C was only inversely related to the risk of postmenopausal $\mathrm{BC}$ in overweight women. ${ }^{[19]}$ In another study, HDL-C has been shown to be inversely associated with $\mathrm{BC}$ risk among premenopausal women, and positively associated with BC risk in postmenopausal women. [20] Some studies demonstrated positive association between TG and postmenopausal BC risk, ${ }^{[16,21]}$ whereas, Bahl et al. established that lipid profile does not affect BC outcome. ${ }^{[4]}$

\subsection{Hypertension and breast cancer}

In the present study, overt hypertension (HTN) was observed in almost $23 \%$ of BC patients. In Jordan, studies that investigate the link between HTN and BC in Jordan are absent. In a study by Hammoudeh et al., the prevalence of HTN in Jordanian healthy population was $63 \%$, which is much higher than the observed results in this study. ${ }^{[8]}$ The prevalence of high systolic blood pressure (SBP) in the present study was $14.1 \%$ and $18.4 \%$ for distolic blood pressure (DBP). This prevalence is high compared to another study by AL-Odat et al., in which it was found that $13.2 \%$ of adult non-BC female had high SBP and/or DBP. ${ }^{[10]}$ The variations may be due to the differences in ethnicity, study design, BC patient's characteristics and sampling technique.

In the present study, SBP, in recently-diagnosed BC and in those taking chemotherapy, was found higher than in newly-diagnosed patients. These findings are consistent with a study by Aparicio-Gallego et al., which concluded high prevalence of HTN in patients taking chemotherapy. ${ }^{[22]}$ The positive association between exposure for chemotherapy and risk of HTN has been also observed by other studies. ${ }^{[23]}$

In this study, the prevalence of both SBP and DBP is higher in postmenopausal than premenopausal women. This result is consistent with a Latin American study, where both SBP and DBP were associated with increased $\mathrm{BC}$ risk in postmenopausal women, a matter that suggests the role of increased insulin resistance and obesity. ${ }^{[24]}$ Similar results have been reported by other studies. ${ }^{[25]}$ However, in a study by Agnoli et al., HTN was insignificantly associated to postmenopausal BC patients. ${ }^{[16]}$

The available evidence regarding the relationship between $\mathrm{HTN}$ and $\mathrm{BC}$ risk are inconsistent and variable. [26] In the present study, both SBP and DBP were correlated with HOMA, whereas DBP was strongly correlated to WC and central obesity; there are other studies that showed positive correlation between HTN and insulin resistance. ${ }^{[27]}$ Former Jordanian studies established a high prevalence of insulin resistance and obesity indices among $\mathrm{BC}$ women. ${ }^{[28,29]}$ Obesity is a risk factor for both postmenopausal BC and HTN. ${ }^{[24]}$ Studies in which BMI is controlled, the relation between HTN and $B C$ was found to be significant with $20 \%$ increased risk of $\mathrm{BC}$ in postmenopausal women with HTN. ${ }^{[25]}$ However, a study by Peeters et al. demonstrated the opposite results and findings. ${ }^{[30]}$

In conclusion, dyslipidemic and hypertensive biomarkers were prevalent among BC patients. Moreover, the risk increased with obesity and age, as it was higher in postmenopausal BC women. Furthermore, treatments' exposure especially to chemotherapy increased the risk of dyslipidemia and hypertension. This may be considered as biomarker for BC prognosis after exposure to treatments and warranted a closer attention by health care professionals, in order to improved outcomes after diagnosis and treatment exposure with more concern regarding postmenopausal BC women.

To the best of authors' knowledge, this study is the first in Jordan to evaluate the concomitance between lipid profile and HTN among BC women. As for limitations, however, the study suffered from limited sample size since it was conducted in only one tertiary hospital. Moreover, there are some structural limitations regarding the study design.

\section{Acknowledgements}

We thank the study's patients for the opportunity to review their medical records and agreed to share in this study regardless of their critical condition. Also, we would like to appreciate the support and collaboration that was provided by the medical team of breast cancer clinic in the Royal medical services.

\section{Financial disclosure}

Funds are obtained from the Deanship of Academic Research at The University of Jordan and Princess Eman Center for Laboratory Research and Science in Royal medical services 2013/2014.

\section{Conflict of interest}

None declared. 


\section{References}

[1] Jemal A, Siegel R, Ward E, Hao Y, Xu J, Thun MJ. Cancer statistics. CA Cancer J Clin 2009; 59: 225249.

[2] Parkin DM, Boyd L, Walker LC. The fraction of cancer attributable to lifestyle and environmental factors in the UK in. Summary and conclusions. $\mathrm{Br}$ J Cancer.2011; 105, 77-81.

[3] Xue F, Michels KB. Diabetes, metabolic syndrome, and breast cancer: a review of the current evidence. Am J ClinNutr. 2007; 86(3): s823-s835.

[4] Bahl M., Ennis M, Tannock IF, Hux JE, Pritchard, $\mathrm{KI}, \mathrm{Koo} \mathrm{J}$ et al. Serum lipids and outcome of earlystage breast cancer: results of a prospective cohort study. Breast Cancer Res Treat.2005; 94:135-144.

[5] Franky DS, Shilin NS, Pankaj MS, Patel HR, Prabhudas SP. Significance of alterations in plasma lipid profile levels in breast cancer. Integr Cancer Ther.2008; 7: 33-41.

[6] Shah FD. Shukla SN, Shah PM, Patel RH, PatelPS. Significance of Alterations in Plasma Lipid Profile Levels in Breast Cancer. Integrative Cancer Therapies. 2008; 7(1): 33-41.

[7] Braithwaite D,Tammemagi CM, Moore DH,Ozanne EM, Hiatt RA, Belkora J, et al. Hypertension is an independent predictor of survival disparity between African-American and white breast cancer patients. Int J Cancer. 2009; 124:1213-1219.

[8] Hammoudeh A, Al-Tarawneh $\mathrm{H}$, Elharassis A, Haddad J, Mahadeen Z, Badran N,et al. Prevalence of conventional risk factors in Jordanians with coronary heart disease: the Jordan hyperlipidemia and related targets study (JoHARTS). INT J CARDIOL. 2006; 110: 179-183.

[9] Khader Y,Batieha A, El-Khateeb M, Al-Omari M, Ajlouni K. Prevalence of dyslipidemia and its associated factors among Jordanian adults. Journal of Clinical Lipidology. 2010; 4: 53-58.

[10] Al-Odat A, Ahmad MN, Haddad F: References of Anthropometric Indices of Central Obesity and Metabolic Syndrome in Jordanian Men and Women. Diabetes Metab Syndrome: Clin Res Rev2012; 6: 15-21.

[11] Al-Tarawneh M, Arkoob K, Al-Nsour M, Al-Nemry O, Al-Hajawi B: Epidemiology of breast cancer in women in Jordan: patient characteristics and survival analysis. EMH J 2009; 16(10):1032-1038.

[12] Lee RD, Nieman DC. Nutrational Assessement, 5th edn, New Yourk: McGraw-Hill. 2010

[13] Obesity: Preventing and Managing the Global Epidemic. 2000, World Health Organization, Report of a WHO Consultation (WHO Technical
Report Series 894) http://www.who.int/nutrition/ publications/obesity/WHO_TRS_894/en/

[14] Matthews DR. Homeostasis model assessment: insulin resistance and beta-cell function from fasting plasma glucose and insulin concentrations in man. Diabetologia 1985; 28: 412-419.

[15] Alberti KG,Eckel RH, Grundy SM, Zimmet PZ, Cleeman JI, Donato KA et al. Harmonizing the metabolic syndrome: a joint interim statement of the International Diabetes Federation Task Force on Epidemiology and Prevention; National Heart, Lung, and Blood Institute; American Heart Association; World Heart Federation; International Atherosclerosis Society; and International Association for the Study of Obesity. Circulation. 2009; 120:1640-1645.

[16] Agnoli C, Berrino F, Abagnato A, Muti P, Panico $S$, Crosignani $P$, et al. Metabolic syndrome and postmenopausal breast cancer in the ORDET cohort: a nested case-control study. NutrMetabCardiovasc Dis2010; 20: 41-48.

[17] Chahil TJ, Ginsberg HN. Diabetic dyslipidaemia. EndocrinMetab Clinic North Amer. 2006; 35: 491510.

[18] Bjorge T, Lukanova A, Jonsson H, Tretli S, Ulmer $\mathrm{H}$, Manier J,et al. Metabolic syndrome and breast cancer in the me-can (metabolic syndrome and cancer) project. Cancer Epidemiol Biomarkers Prev. 2010; 19(7): 1737-1745.

[19] Furberg AS, Veierod MB,Wilsgaard T, Bernstein L, Thune I. Serum high-density lipoprotein cholesterol, metabolic profil, and breast cancer risk. J Natl Cancer Inst. 2004; 96: 1152-1160.

[20] Moorman PG, Hulka BS, Hiatt RA. Association between high density lipoprotein cholesterol and breast cancer varies by menopausal status. Cancer Epidemiol Biomarkers Prev. 1998; 7(6): 483-8.

[21] AlschulerL. Reducing risk of breast cancer by focusing on metabolic parameters. Nat Med J. 2013; 5: 10-14.

[22] Aparicio-Gallego G, Afonso-Afonso F, Leon-Mateos L, Firvida-Perez J, Vazquez-Estevez S, LazaroQuintela M. Molecular basis of hypertension side effects induced by sunitinib. Anticancer Drugs. 2011; 22(1): 1-8.

[23] Mouhayar E, Salahudeen A. Hypertension in cancer patients. Tex Heart Inst J. 2011; 38(3): 263-5.

[24] Pereira A, Garmendial ML, Alvarado ME, Albala C. Hypertension and the Risk of Breast Cancer in Chilean Women: a Case-control Study. Asian Pacific Journal of Cancer Prevention. 2012; 13(11): 5829-5834. 
[25] Rosato V, Bosetti C, Talamini R, Levi F, Montella $\mathrm{M}$, GiacosaA, et al. Metabolic syndrome and the risk of breast cancer in postmenopausal women. Ann Oncol.2011. Retrievedfrom http://annonc. oxfordjournals.org/ content/early/ 2011/ 03 /17/ annonc.mdr025.

[26] Reeves KW, McLaughlin V,Fredman L, Ensrud K, Cauley JA. Components of metabolic syndrome and risk of breast cancer by prognostic features in the study of osteoporotic fractures cohort. Cancer Causes Control.2012; 23(8):1241-1251.

[27] Park YM, Kwon HS,Lim SY, Lee JH, Yoon KH, Son HY,et al. Optimal Waist Circumference Cut-off Value Reflecting Insulin Resistance as a Diagnostic Criterion of Metabolic Syndrome in a Nondiabetic Korean Population Aged 40 Years and Over: The Chungju Metabolic Disease Cohort (CMC) Study. Yonsei Med J. 2010;51(4):511-518.

[28] Peeters PH, Van Noord PA, Hoes AW, Fracheboud J, Gimbrere $\mathrm{CH}$, Grobbee DE. Hypertension and breast cancer risk in a 19-year follow-up study (the DOM cohort). Diagnostic investigation into mammarian cancer. J Hypert. 2000; 18: 249-254.

[29] Al-Zeidaneen S, Ahmad M, Al-Ebouse A, Hamad AW: Interactive role of obesity indices on breast cancer severity in Jordanian women. ejbps. 2017; 4(6): 637-644.

[30] Al-Zeidaneen S, Ahmad M, Al-Ebouse A. The Impact of Treatment Exposure on Diabetes Biomarkers among Jordanian Breast Cancer Women: A Connection through FBG, C-Peptide and HOMA-IR. Curr Gynecol Oncol. 2017;15 (4), pp. 231-238. DOI: 10.15557/CGO.2017.0022 